ethanol. Phenotyping and genotyping CYP2E1 is of great interest as several mutations, described in the CYP2E1 gene, could lead to modifications of the enzymes activity and could thus be related to alcoholism or certain cancers.

A non-traumatic method was recently proposed to measured CYP2E1 activity in vivo. Patients were administered a tablet of chlorzoxazone and blood was withdrawn 2 h later. The 6-hydroxy-chlorzoxazone/ chlorzoxazone ratio was determined, as previously described, using HPLC (Lucas et al (1993) J Chromatogr 622, 79-86). This ratio was found to be $0.34 \pm 0.15$ in controls ( $n=$ 30 ) and $1.43 \pm 0.6$ in alcoholics after $24 \mathrm{~h}$ withdrawal $(n=20)$, providing a reliable test for CYP2E1 phenotyping.

For genotyping, a mutation located on the $5^{\prime}$ flanking region of the gene (Hayashi et al (1991) J Biochem 110, 559-565) was determined after the appropriate PCR amplification and digestion of the fragment with Rsa I or Pst I restriction enzymes. The frequency of this mutation was studied in 620 alcoholic and 226 control Caucasians and no difference was demonstrated between the 2 groups $(6.93 \%$ were heterozygous for this mutation in alcoholics vs $5.31 \%$ in controls). The frequency of this mutation seemed to be enhanced in alcoholic patients with ORL cancers $(10.6 \%, n=66)$ whereas it was decreased in patients with an oesophageal carcinoma (no mutation, $n=$ 56) although this was not statistically significant.

To date, there is no evidence of modified CYP2E1 activity following gene mutation. Further studies including CYP2E1 phenotyping and genotyping in the same subject are required in order to be able to draw a clear conclusion.

Grant from IREB, 94/04.

\section{Sulfur amino acid requirements for the maintenance and growth of juvenile rain-}

bow trout. M Mambrini, L Seudre (Laboratoire de nutrition des poissons, unité mixte INRA/IFREMER, station d'hydrobiologie, 64310 Saint-Pée-sur-Nivelle, France)

The sulfur amino acid (SAA) requirements for the maintenance and protein accretion of rainbow trout reared at $16^{\circ} \mathrm{C}$ were estimated by fitting a linear regression between SAA intake and nitrogen ( $\mathrm{N}$ ) balance. The SAA needs for maintenance and growth (for $1 \mathrm{~g} \mathrm{~N}$ accretion) correspond respectively to the $x$-intercept and the reciprocal of the slope (Fuller et al (1989) Br J Nutr 62, 255-267). Semi-synthetic diets were formulated to contain increasing $N$ levels $(0,2.4,4.8$ and $8.0 \%$ DM), using crystalline amino acids and casein, having a composition comparable to the amino acid profile of the fish whole body. The assay consisted of verifying the linearity when the SAA supply was reduced (0 for the diet containing $2.4 \%$ and $-20 \%$ for diets containing 4.8 and $8.0 \% \mathrm{~N}$ ). The diets

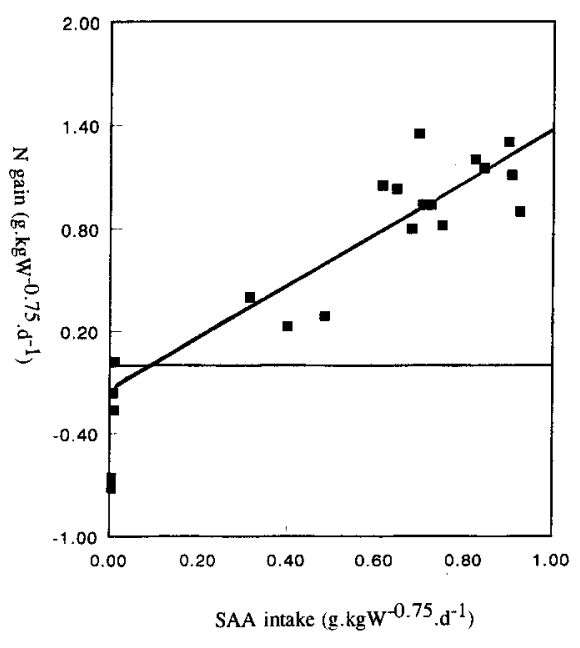

Fig 1. Relationship between nitrogen gain and sulfur amino acid (SAA) intake in rainbow trout $(70 \mathrm{~g})$ given diets with increasing amounts of nitrogen with either an amino acid profile similar to that of trout whole body or with specific deletion of SAA. (Mambrini and Seudre.) 
were fed ad libitum to triplicate groups of 20 trout ( $70 \mathrm{~g}$ mean body weight) for a period of $21 \mathrm{~d}$. The intake and growth were recorded; 10 fish in each tank were slaughtered at both the beginning and the end of the period to determine $\mathrm{N}$ content of the carcass.

Withdrawal of all dietary SAA resulted in a lower body $\mathrm{N}$ loss than that observed with the protein-free diet. On average, a 20\% reduction of the SAA supply did not have any significant effect on the $\mathrm{N}$ gain (fig 1). But, to high between-tank variation (residual CV: $29 \%$ for SAA intake and $N$ gain), the $N$ gain linearly increased with SAA intake $(r=$ $0.92 ; n=18$ ). The sulfur amino acid requirement for maintenance was $97 \mathrm{mg} / \mathrm{kg}$ W $0.75 / \mathrm{d}$ and that for growth was $663 \mathrm{mg} / \mathrm{g} \mathrm{N}$ gain, respectively 2 and 3 fold higher than those estimated for pigs (Fuller et al, 1989). For a trout weighing $100 \mathrm{~g}$, about $14 \%$ of the SAA ingested would be utilized for maintenance.

\section{Protein metabolism response to feeding is dependent on age and gender. $Y$ Boirie, $\mathrm{P}$ Rousset, B Beaufrère (Université Cler- mont-Auvergne, laboratoire de nutrition humaine, CRNH, BP 321, 63009 Clermont- Ferrand, France)}

Body composition is modified during aging but the reason for the decreased lean body mass (LBM) is unknown. To examine the whole-body protein metabolism response to feeding in the elderly, we studied 6 young men (YM), 6 young women (YW), 6 old men $(\mathrm{OM})$ and 6 old women (OW). Their mean age and $\mathrm{BMI}$ were 22.6, 21.5, 68.2, 68.3 years and $21.3,22.0,26.1,24.5 \mathrm{~kg} / \mathrm{m}^{2}$ for YM, YW, OM, OW respectively. Leucine flux (Leu F) and oxidation (Leu OX) were determined with a $\left[1-{ }^{13} \mathrm{C}\right]$ leucine infusion after an overnight fast and during the ingestion of a defined test meal $(10 \mathrm{kcal} / \mathrm{kg}$ ) containing $15.6 \%$ protein and administered orally every $15 \mathrm{~min}$, for $240 \mathrm{~min}$ (dietary leucine intake: $1.40 \mu \mathrm{mol} / \mathrm{kg} . \mathrm{min}$ ). The LBM was estimated by bio-electrical impedance analysis using specific geriatric equations.

During fasting, the Leu $\mathrm{F}$ was greater in the younger than the older subjects $(1.47 \pm$ 0.18 vs $1.23 \pm 0.14 \mu \mathrm{mol} / \mathrm{kg}$.min, mean \pm $\mathrm{SD}, p<0.001$ ) without any difference between men and women. Expressed per $\mathrm{kg} L B M$, the Leu $F$ were not different between the groups except for OW, who had a higher Leu $\mathrm{F}(2.19 \pm 0.27$ vs $1.82 \pm$ $0.2,1.85 \pm 0.16,1.98 \pm 0.23$ for OW $v s \mathrm{YM}$, $\mathrm{YX}, \mathrm{OM}, p<0.05)$. Feeding was associated with an accelerated Leu $F$ in all groups but the Leu $F$ in OW, expressed as $\mu \mathrm{mol} / \mathrm{kg}$ LBM.min, was much greater than in the 3 other groups $(3.30 \pm 0.38$ vs $2.35 \pm 0.16$, $2.21 \pm 0.25,2.50 \pm 0.4$ for OW vs YM, YW, $\mathrm{OM}, p<0.01)$.

The Leu Ox was different between the YM-YW, YM-OM and YW-OW groups during fasting but was totally normalized in all groups when expressed per kg LBM $(0.48 \pm$ $0.04,0.42 \pm 0.06,0.46 \pm 0.08,0.46 \pm 0.07$, NS). The Leu $O x$ increase during feeding was particularly elevated in the OW group, the difference was amplified when expressed per kg LBM (1.89 \pm 0.28 vs 1.18 $\pm 0.13,1.12 \pm 0.08,1.03 \pm 0.19$, for $O W$ vs YM, YW, OM, $p<0.001$ ).

The main finding of this study was therefore an increased leucine oxidation in elderly women during feeding, which might be a factor in the loss of body proteins. These gender modifications of protein metabolism need to be considered in amino acid kinetic studies and for the protein requirements of elderly people. 